\title{
Comparative Evaluation of a Point-of-Care Immunochromatographic Test SNAP 4Dx with Molecular Detection Tests for Vector-Borne Canine Pathogens in Hong Kong
}

\author{
Samson S.Y. Wong, ${ }^{1,2, *}$ Jade L.L. Teng, ${ }^{1,2,{ }^{*}}$ Rosana W.S. Poon, ${ }^{1,2}$ Garnet K.Y. Choi, ${ }^{1,2}$ \\ Kwok-Hung Chan, ${ }^{1,2}$ Michelle L. Yeung, ${ }^{3}$ Janet J.Y. Hui, ${ }^{4}$ and Kwok-Yung Yuen ${ }^{1,2}$
}

\begin{abstract}
There are no comprehensive studies on the performance of commonly used point-of-care diagnostic enzyme immunoassay for common arthropod-borne canine pathogens. A comparative evaluation of an immunochromatographic test for these infections with a comprehensive polymerase chain reaction (PCR) test panel was performed on 100 pet dogs and 100 stray dogs without obvious clinical symptoms. Of the 162 positive test results from both immunochromatographic test and PCR, there was $85.2 \%$ concordance. The 24 discordant results between serology and PCR occurred in tests involving Ehrlichia canis (14) and Anaplasma platys (10), which may be related to the time of infection. No positive cases of borreliosis or rickettsiosis were detected. One important limitation of the immunochromatographic test was its lack of testing for babesiosis and hepatozoonosis. The former is the most prevalent arthropod-borne canine infection in our cohort (41\%). Coinfections were found in 19\% stray dogs and $6 \%$ of pet dogs with both tests $(p<0.01)$. Seventeen and 8 samples from stray and pet dogs, respectively, were initially positive in the PCR test for Ehrlichia. However, on sequencing of the PCR amplicon, 10 from stray and 2 from pet dogs were found to be Wolbachia sequences instead, with $100 \%$ nucleotide identity to the $16 \mathrm{~S}$ rRNA sequence of Wolbachia endosymbiont of Dirofilaria immitis. The presence of Wolbachia DNAemia (6\%) correlated well with the molecular test and immunochromatographic antigen test for D. immitis.
\end{abstract}

Key Words: Anaplasma platys—Babesia—Dirofilaria immitis—Ehrlichia—Wolbachia.

\section{Introduction}

E HRLICHIOSIS, ANAPLASMOSIS, borreliosis, and dirofilariasis are important arthropod-borne canine infections that are often diagnosed on the basis of the results from pointof-care testing at the veterinary practice. Immunochromatographic assays such as SNAP 3Dx and 4Dx (IDEXX Laboratories, Westbrook, ME) are commonly used for rapid diagnostic purposes. Most of the tests detect antibodies that may indicate past exposure instead of active infection. Only the test for Dirofilaria immitis detects specific parasitic circu- lating antigen. There are, however, few comparative evaluations on the performance of these assays against other diagnostic techniques. Previous studies on zoonotic pathogens suggested that nucleic acid amplification tests are both sensitive and specific for active infection (Littman 2003, Lau et al. 2005, 2008, 2010, Woo et al. 2009, Ayoob et al. 2010, Gioia et al. 2010, Irwin 2010, Little 2010, Veir and Lappin 2010). Although some pathogens may not cause symptomatic disease, accurate diagnosis is still important, as the infected animals may serve as transport hosts for dissemination of the pathogens or infected ectoparasitic vectors. The primary aim

\footnotetext{
${ }^{1}$ State Key Laboratory of Emerging Infectious Diseases, Department of Microbiology, The University of Hong Kong, Hong Kong

${ }^{2}$ Research Centre of Infection and Immunology, The University of Hong Kong, Hong Kong.

${ }^{3}$ Agriculture, Fisheries and Conservation Department, Hong Kong Special Administrative Region, Hong Kong.

${ }^{4}$ PathLab Medical Laboratories Ltd., Hong Kong.

*These two authors contributed equally to this work and are co-first authors.
} 


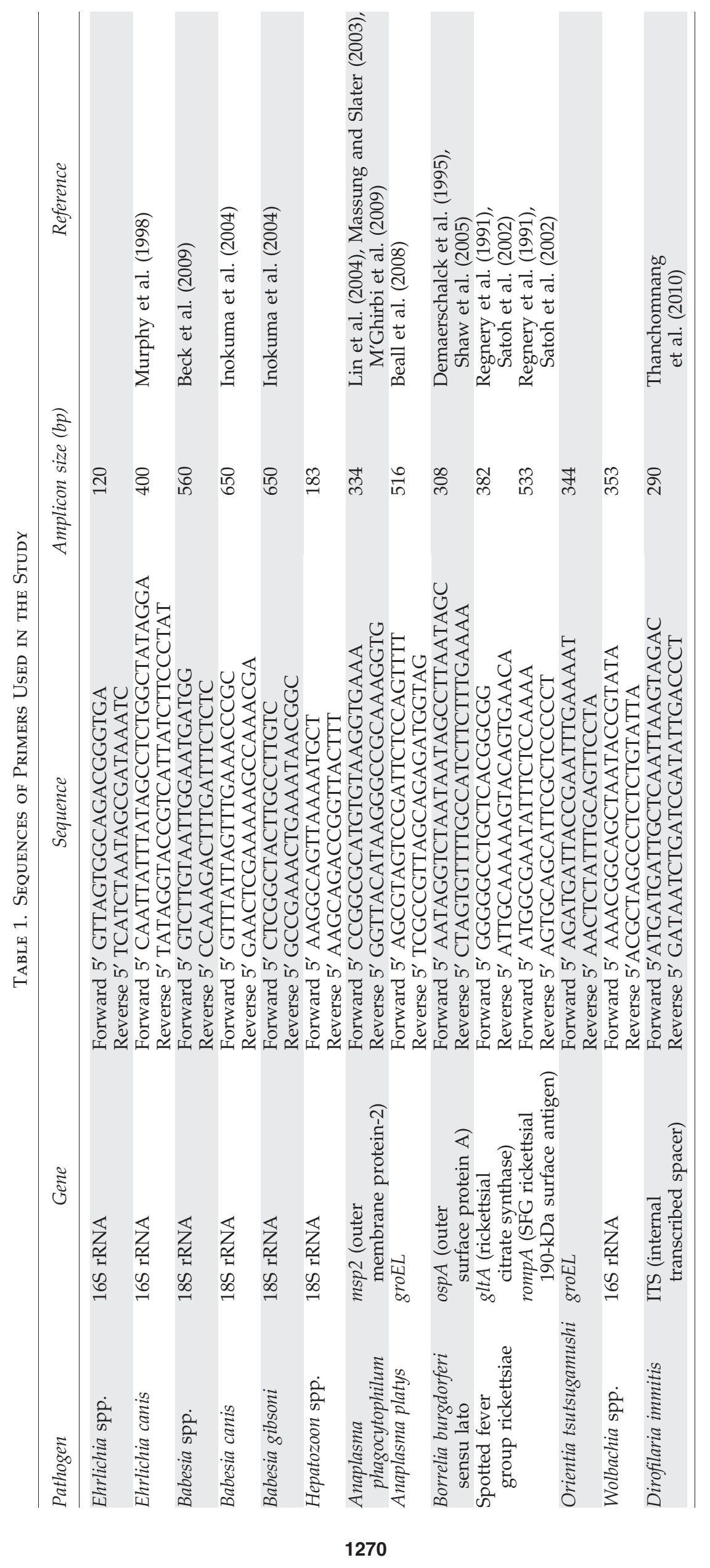


of our study is to evaluate the performance of the SNAP 4Dx kit against a panel of newly developed rapid molecular diagnostic tests for important canine vector-borne infections in Hong Kong. The secondary aim of our study is to determine the prevalence of these zoonotic infections in Hong Kong, which has not been systematically defined earlier. In addition to Ehrlichia, Anaplasma, Borrelia, and D. immitis, we also tested for Babesia, Hepatozoon, Rickettsia, and Orientia tsutsugamushi, for which there are currently no commercial point-of-care tests available.

\section{Materials and Methods}

\section{Animals}

Two groups of dogs were included in the study. The first group were pet dogs $(n=100)$ brought to the care of veterinarians for routine health checking from March to July 2010. After clinical evaluation, relevant specimens were sent to a veterinary pathologist for laboratory investigations. Peripheral EDTA blood was taken, and the plasma was tested by the SNAP 4Dx for antibodies against Anaplasma phagocytophilum, Ehrlichia canis, Borrelia burgdorferi, and D. immitis antigen. The second group were stray dogs $(n=100)$ captured by the government Agriculture, Fisheries, and Conservation Department from June 2009 to January 2010. EDTA blood samples were collected by veterinarians in the kennels during euthanasia for polymerase chain reaction (PCR) and SNAP 4Dx testing.

\section{Immunochromatographic assay}

SNAP 4Dx test was performed according to the manufacturer's instructions by the same investigator.

\section{PCR and DNA sequencing for blood pathogens}

DNA was extracted from EDTA whole blood samples using EZ1 mini kit (QIAgen, Hilden, Germany) according to the manufacturer's instructions. The DNA was eluted in elution buffer and was used as the template for PCR. The primer sequences are listed in Table 1. The sequences of the PCR products were compared with known sequences by BLAST analysis against the NCBI database (Yuen et al. 2001).

\section{Quantitative PCR}

Quantitative PCR was performed on the PCR-positive samples (14 for E. canis and 81 for Babesia) using TaqMan Universal PCR Master Mix with StepOnePlus Real-Time PCR System (Applied Biosystems, Foster City, CA) (Lau et al. 2009). The primers and probes are listed in Table 2 . This set of quantitative PCR primers and probe for Ehrlichia does not cross amplify Wolbachia. Two plasmids containing the target sequences were used for generating the standard curves. The limit of detection for either species is 10 plasmid copies per reaction.

\section{Phylogenetic characterization}

Phylogenetic tree was constructed by the neighbor-joining method using Kimura's two-parameter correction with ClustalX 1.83. The 316, 292, 338, 150, 264, and $171 \mathrm{bp}$ of amplicons from the 16S rRNA of E. canis, 16S rRNA of Wolbachia endosymbioint of $D$. immitis, $18 \mathrm{~S}$ rRNA of Babesia, 18S rRNA of Hepatozoon canis, groEL of Anaplasma platys, and ITS of $D$. immitis, respectively, from all positive samples were included in the analysis.

\section{Data analysis}

The chi-square test and Student's $t$-test were used where appropriate to assess whether data obtained in the two groups of dogs significantly differed. A $p$-value of $<0.05$ is considered statistically significant.

\section{Nucleotide sequence accession numbers}

Partial nucleotide sequences of $16 \mathrm{~S}$ rRNA gene (E. canis and Wolbachia endosymbiont of $D$. immitis), 18S rRNA gene ( $B a-$ besia gibsoni, Babesia canis, and H. canis), groEL gene (A. platys), and ITS (D. immitis) obtained in this study have been lodged within the GenBank sequence database under accession numbers HQ718601 to HQ718730.

\section{Results}

\section{Comparison between SNAP 4Dx and PCR}

There were 162 positive test results from both SNAP 4Dx and PCR with $85.2 \%$ concordance between the two tests. The results were summarized in Table 3. Concordance between SNAP 4Dx and PCR was $100 \%$ for D. immitis. Discrepancies between serologic and PCR results were observed for 24 test results (Table 4) involving E. canis and A. platys. Thirteen samples had positive serology but negative PCR for the respective pathogens, whereas 3 A. platys and 8 E. canis samples had positive PCR but negative serology results.

\section{Prevalence of individual pathogens}

We did not find any B. burgdorferi, Rickettsia, and O. tsutsugamushi infection in our samples. The commonest pathogen detected is Babesia, which is present in $48 \%$ and $33 \%$ of stray

Table 2. Primers and Probes Used for Quantitative Polymerase Chain Reaction of EHRLICHIA-AND BABESIA-POSITIVE SAMPLES

\begin{tabular}{lllc}
\hline Pathogen (gene) & Primers/probes & \multicolumn{1}{c}{ Sequences } & Product length $(\mathrm{bp})$ \\
\hline Ehrlichia spp. (16S rRNA) & Forward & 5'CGGGTGAGTAATGCGTAGGAAT & 82 \\
& Reverse & 5'CCCKCRGGGATTATACAGTATTACC & \\
& Probe & 5' [FAM]TACCTAGTAGTAYGGATAGCCAT [MGB] & \\
Babesia spp. (18S rRNA) & Forward & 5'GACTAGDGATGGAGGTCGTCRT & 79 \\
& Reverse & 5'TCCCCCAGAACCCAAAG & \\
& Probe & 5' [FAM] CCTTCAGSAVCTTGAGAGA [MGB] & \\
\hline
\end{tabular}


Table 3. Results of SNAP 4Dx and Polymerase Chain Reaction for Canine Arthropod-Borne Pathogens

\begin{tabular}{|c|c|c|c|c|c|c|}
\hline & \multicolumn{3}{|c|}{ Stray dogs $(\mathrm{n}=100)$} & \multicolumn{3}{|c|}{ Pet dogs $(\mathrm{n}=100)$} \\
\hline & $\begin{array}{l}\text { Number } \\
\text { positive } \\
\text { for tests }\end{array}$ & $\begin{array}{l}\text { Speciation by } \\
\text { sequencing }\end{array}$ & $\begin{array}{c}\text { DNA load } \\
\text { in blood (mean, } \\
\text { [range] copies } / m L)\end{array}$ & $\begin{array}{l}\text { Number } \\
\text { positive } \\
\text { for tests }\end{array}$ & $\begin{array}{l}\text { Speciation by } \\
\text { sequencing }\end{array}$ & $\begin{array}{c}\text { DNA load } \\
\text { in blood } \\
\text { (mean, [range] } \\
\text { copies } / \mathrm{mL} \text { ) }\end{array}$ \\
\hline \multicolumn{7}{|l|}{ PCR } \\
\hline Borrelia burgdorferi & 0 & & & 0 & & \\
\hline Rickettsia spp. & 0 & & & 0 & & \\
\hline O. tsutsugamushi & 0 & & & 0 & & \\
\hline Anaplasma spp. & 8 & A. platys (8) & & 0 & & \\
\hline Ehrlichia spp. & 8 & E. canis (7) & $\begin{array}{c}2.25 \times 10^{5} \\
{\left[2.50 \times 10^{1} \text { to } 1.43 \times 10^{6}\right]}\end{array}$ & 6 & E. canis (6) & $\begin{array}{l}\quad 9.08 \times 10^{4} \\
{\left[6.88 \times 10^{2}\right.} \\
\left.\text { to } 4.03 \times 10^{5}\right]\end{array}$ \\
\hline Wolbachia spp. & 10 & & & 2 & & \\
\hline Babesia spp. & 48 & B. canis $(4)$ & $\begin{array}{c}2.26 \times 10^{6} \\
{\left[1.40 \times 10^{4} \text { to } 2.05 \times 10^{6}\right]}\end{array}$ & 33 & B. canis (2), & $\begin{array}{l}4.8 \times 10^{7} \\
{\left[7.74 \times 10^{5}\right.}\end{array}$ \\
\hline & & B. gibsoni (44) & {$\left[8.86 \times 10^{3}\right.$ to $\left.1.75 \times 10^{7}\right]$} & & B. gibsoni (31) & $\begin{array}{l}\left.\text { to } 5.08 \times 10^{6}\right] \\
{\left[1.61 \times 10^{4}\right.} \\
\left.\quad \text { to } 4.29 \times 10^{8}\right]\end{array}$ \\
\hline Hepatozoon spp. & 2 & H. canis (2) & & 1 & H. canis $(1)$ & \\
\hline D. immitis & 10 & & & 2 & & \\
\hline \multicolumn{7}{|l|}{ SNAP 4Dx } \\
\hline D. immitis & 10 & & & 2 & & \\
\hline E. canis $+A$. phagocytophilum & 1 & & & 3 & & \\
\hline E. canis only & 1 & & & 7 & & \\
\hline A. phagocytophilum only & 6 & & & 0 & & \\
\hline A. phagocytophilum $+D$. immitis & 2 & & & & & \\
\hline B. burgdorferi & 0 & & & 0 & & \\
\hline Co-infections ${ }^{\mathrm{a}}$ & 19 & & & 6 & & \\
\hline Babesia + E. canis & 3 & & & 1 & & \\
\hline Babesia + D. immitis & & & & 1 & & \\
\hline Babesia $+H$. canis & & & & 1 & & \\
\hline E. canis + Anaplasma & 7 & & & 3 & & \\
\hline D. immitis $+H$. canis & 2 & & & & & \\
\hline Babesia + E. canis + Anaplasma & 2 & & & & & \\
\hline Anaplasma $+D$. immitis $+H$. canis & 1 & & & & & \\
\hline
\end{tabular}

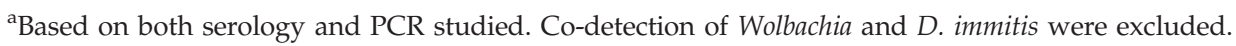

$\mathrm{PCR}$, polymerase chain reaction.

and pet dogs, respectively $(p<0.05)$. Quantitative PCR test showed that there is a significantly higher Babesia DNA copy number in pet versus stray dogs $\left(4.8 \times 10^{7}\right.$ vs. $2.26 \times 10^{6}$ copies / $\mathrm{mL})(p<0.005)$. Sequencing of the $18 \mathrm{~S}$ rRNA gene showed that most of the Babesia positive cases are B. gibsoni (accounting for $91.6 \%$ [stray] and $93.9 \%$ [pet]) rather than B. canis, all of the latter are B. canis subspecies vogeli.

The prevalence of E. canis was of $8 \%$ and $6 \%$ in stray and pet dogs, respectively. There are no significant differences in the prevalence and DNA copy number between the two groups of dogs $(p>0.5)$. E. canis antibodies were found in 2 stray and 10 pet dogs; 1 and 3 dogs, respectively, from the two groups were also positive for Anaplasma antibodies. In the two E. canis antibody-positive stray dogs, the one that was positive for both Ehrlichia and Anaplasma antibodies was PCR-positive for E. canis $\left(1.07 \times 10^{5}\right.$ copies $\left./ \mathrm{mL}\right)$ but PCR-negative for Anaplasma. The one that was positive for $E$. canis antibody alone had a very weak color change on SNAP 4Dx, and the sample was PCR-negative for E. canis. In the 10 pet dogs with positive E. canis antibodies, 5 of them were PCR-negative, suggesting that the antibodies represented a past infection. On the other hand, 1 pet and 2 stray dogs had positive E. canis PCR (ranging from $1.13 \times 10^{5}$ to $1.43 \times 10^{6}$ copies $/ \mathrm{mL}$ ) but negative E. canis antibodies on SNAP 4Dx. We suspect that these may represent a hyperacute ehrlichial infection before detectable antibodies were developed in the infected dogs.

The prevalence of anaplasmosis was $8 \%$ and $0 \%$ in stray and pet dogs, respectively. Anaplasma antibodies were present in 12 dogs (9 stray and 3 pet), either alone (6 stray) or with heartworm (2 stray) or E. canis (1 stray and 3 pet) antibodies. All the pet dogs were PCR-negative for Anaplasma, signifying

Table 4. Discrepant Results Between Serology and Polymerase Chain Reaction

Pathogen Source of dogs Serology $+/ P C R-$ Serology-/PCR +

\begin{tabular}{llll}
\hline E. canis & Strays & 1 & 7 \\
& Pets & 5 & 1 \\
A. platys & Strays & 4 & 3 \\
& Pets & 3 & 0 \\
\end{tabular}


possible past infections. Anaplasma PCR was positive in 8 stray dogs, 6 of which were also PCR positive for E. canis. Sequencing of the groEL amplicon showed that there was 1 $(0.2 \%)$ base difference between our samples and that of $A$. platys (AF4781291) but $>16(3.4 \%$ ) base difference with that of A. phagocytophilum (HM7520981), indicating that all the PCRpositive cases were A. platys (Fig. 1A).

D. immitis DNAemia was found in 12 dogs (10 stray and 2 pet, $p<0.025)$; all of them were positive for circulating heartworm antigen. Sequencing of the ITS showed that all cases have $100 \%$ nucleotide identity to those of the reported strains.

Hepatozoonosis is uncommon in our sample with only $2 \%$ and $1 \%$ prevalence in stray and pet dogs, respectively. Sequencing of the $18 \mathrm{~S}$ rRNA amplicon showed that all belonged to $H$. canis.

Co-infection by 2 or more pathogens was observed in 19\% of stray dogs and $6 \%$ of pet dogs $(p<0.01)$. The combinations of pathogens in dogs with coinfection are shown in Table 3.

\section{Incidental finding of Wolbachia DNAemia}

Seventeen and 8 samples from stray and pet dogs, respectively, were initially positive in the Ehrlichia PCR reaction. However, on sequencing of their PCR amplicons, 10 from stray and 2 from pet dogs were found to be Wolbachia sequences instead, with $100 \%$ nucleotide identity to the $16 \mathrm{~S}$ rRNA sequence of Wolbachia endosymbiont of D. immitis (AF088187) (Fig. 1B). This can be explained by the significant homology between the Ehrlichia and Wolbachia 16S rRNA sequences (Fig. 2). Therefore, we designed another Wolbachiaspecific 16S rRNA primer pair and found that all cases with D. immitis DNAemia also had Wolbachia DNAemia when tested again by Wolbachia-specific PCR test. Sequencing of the $16 \mathrm{~S}$ rRNA gene of these amplicons showed that they are truly Wolbachia endosymbiont of D. immitis but not other dog arthropod-related Wolbachia species (Fig. 1B). False-positive Ehrlichia PCR results were eliminated by the Tagman quantitative PCR for Ehrlichia using a specific probe or PCR primers for E. canis that will not cross react with Wolbachia.

\section{Discussion}

Rapid and accurate detection of veterinary pathogens is important for clinical management of sick animals because of the limited sensitivity and specificity of clinical examination and problems associated with empirical treatment. This is the first systematic study to compare SNAP 4Dx against PCR and determine the prevalence of eight canine vector-borne pathogens in Hong Kong. It provides a better understanding of the strengths and limitations of serologic tests and the local prevalence of these pathogens.

The overall concordance between SNAP 4Dx and PCR is $85.2 \%$. Discrepancies between the commercial immunochromatographic test and our PCR tests involved E. canis and A. platys (Table 4). We suspect that these PCRpositive and antibody-negative cases represented early infections before the development of antibody responses. For example, an E. canis-seronegative dog had one of the highest bacterial DNA load in blood $\left(4.03 \times 10^{5}\right.$ copies $\left./ \mathrm{mL}\right)$. It was presumably diagnosed during acute infection before seroconversion, which shows that molecular tests do have an important role in diagnosis at the hyperacute stage of the disease and are not confounded by positive antibody response due to past ex- posures as in immunochromatographic tests. On the other hand, the antibody-positive but PCR-negative cases may represent past infections that may have been treated, spontaneously resolved, and progressed to the subclinical chronic stage with low levels of bacteremia, or due to cross-reacting antibodies.

Around $10 \%$ of dogs in our study had evidence of Ehrlichia and/or Anaplasma infection by serology or PCR. E. canis is the only Ehrlichia species found in Hong Kong, presumably due to the absence of Amblyomma americanum tick, which is the vector for Ehrlichia ewingii and Ehrlichia chaffeensis.

All the Anaplasma amplicons in our series belonged to A. platys, the vector of which is the brown dog tick Rhipicephalus sanguineus. A. phagocytophilum but not $A$. platys can cause human granulocytic anaplasmosis. The absence of A. phagocytophilum in our study suggests that the risk of autochthonous human granulocytic anaplasmosis is low in Hong Kong. In contrast to A. phagocytophilum, canine infection due to $A$. platys is often asymptomatic despite the presence of recurrent thrombocytopenia. This may explain the $8 \%$ prevalence among apparently healthy stray dogs, which is higher than the prevalence in pet dogs, presumably due to more intense exposure to tick vectors. E. ewingii, E. chaffeensis, Neorickettsia risticii, and Neorickettsia helminthoeca are other canine Anaplasmataceae pathogens, whereas E. chaffeensis and $A$. phagocytophilum also cause human infections.

Although we initially did not specifically look for Wolbachia DNA in our samples, the E. canis primers unexpectedly picked up Wolbachia, which can only be differentiated from E. canis by sequencing the PCR product. This cross reaction could be due to significant homology between their $16 \mathrm{~S}$ rRNA sequences (Fig. 2). The 16S rRNA primers for Ehrlichia and Anaplasma are known to amplify Wolbachia, and sequencing of the PCR products is essential for differentiating the 3 genera of Anaplasmataceae (Unver et al. 2003, Little 2010). Similar findings have also been previously reported when $H$. canis was unexpectedly detected using Babesia primers due to a high degree of homology between the 18S rRNA sequences of the 2 organisms (Spolidorio et al. 2009). Wolbachia are endosymbionts of arthropods and filarial nematodes. Humans and animals with filariasis develop immune responses to Wolbachia antigens, and the pro-inflammatory antigens from Wolbachia participates in the pathogenesis of filariasis and affects the clinical outcome of Dirofilaria infections (Bandi et al. 2001, Bazzocchi et al. 2003, Kramer et al. 2008, Dingman et al. 2010). Elimination of Wolbachia with tetracyclines is clinically beneficial in the treatment of filariasis and can possibly reduce transmission (Rossi et al. 2010).

The prevalence of $D$. immitis is highly variable, ranging from $0.24 \%$ to over $50 \%$ in different countries (Lee et al. 2010). The prevalence of canine heartworm infection is $6 \%$ in Hong Kong, with a significantly higher prevalence among stray than pet dogs, possibly related to the intensity of exposure to mosquito vectors. Accurate diagnosis is important, because the infection can result in severe cardiopulmonary disease. Diagnosis is commonly made by either blood smear examination by the modified Knott's method or antigen detection. In recent years, molecular diagnosis by using PCR to detect $D$. immitis DNA in canine blood is also possible. We found $100 \%$ concordance between SNAP 4Dx and PCR for the diagnosis of $D$. immitis infection, and all dogs with $D$. immitis infection also had positive Wolbachia PCR. Unfortunately, since the detection of Wolbachia DNAemia was not initially planned as part 
A

Ehrlichia canis (U967311)

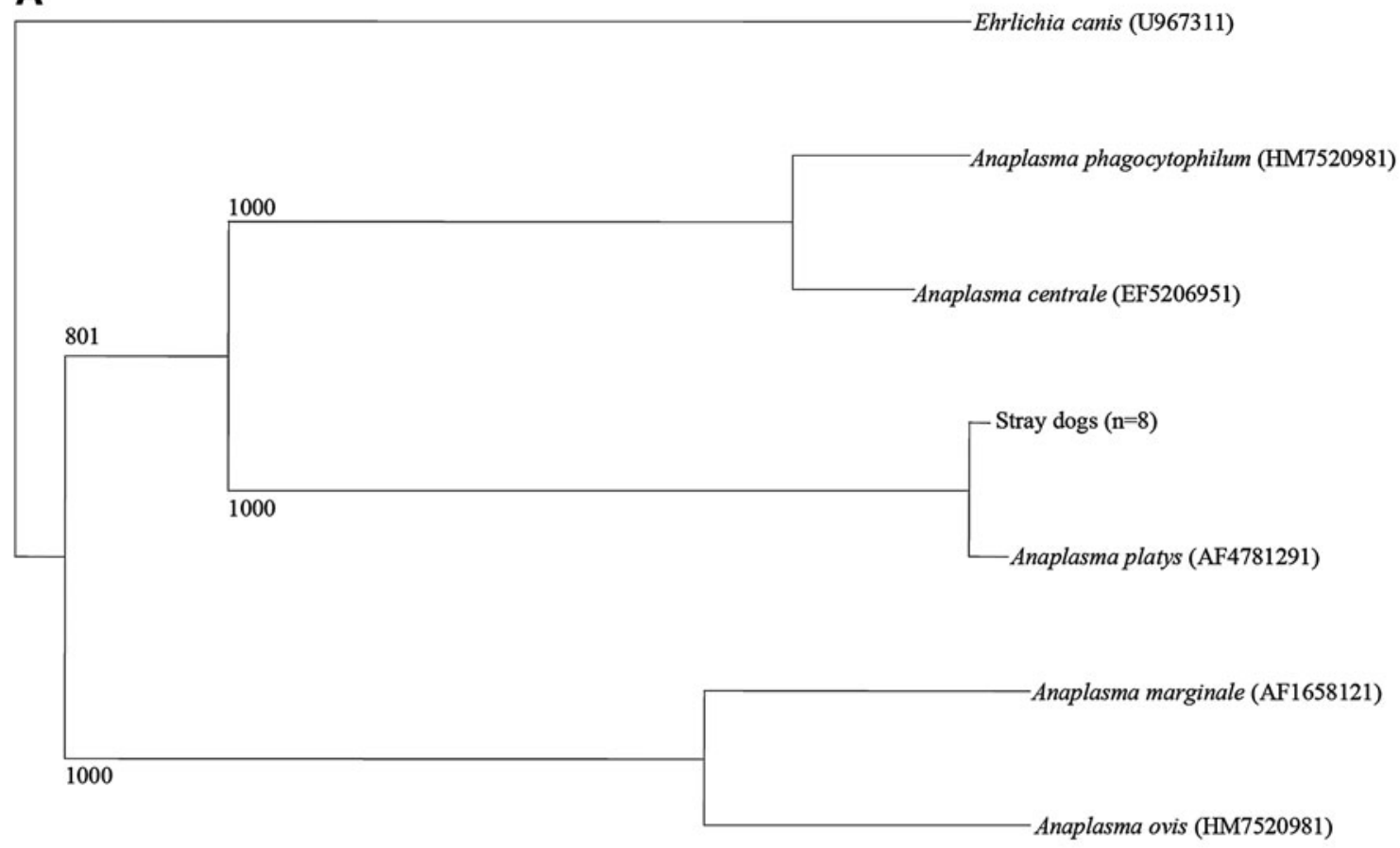

B

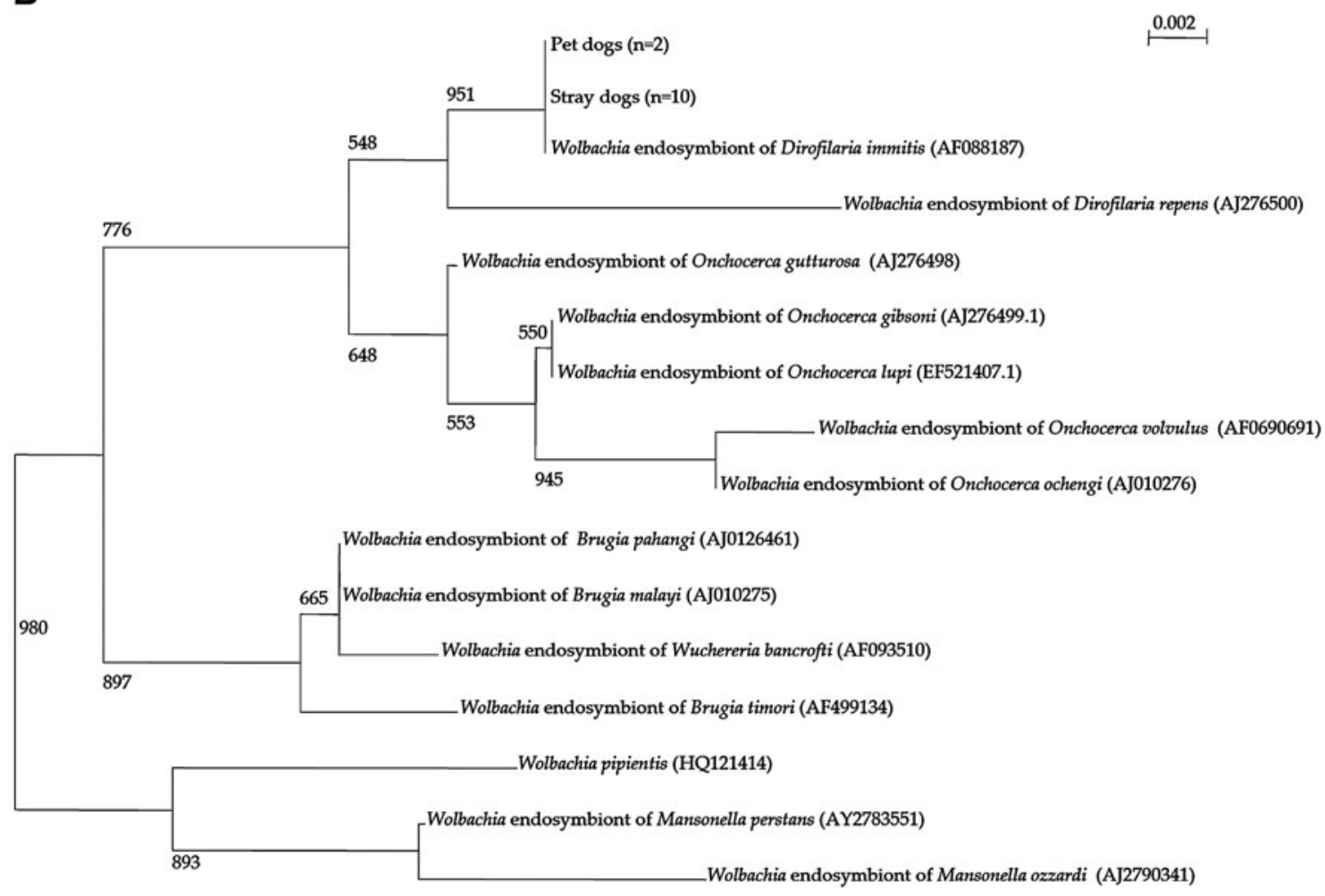

FIG. 1. Phylogenetic relationships based on sequences identified in this study. (A) Anaplasma platys, groEL gene; (B) Wolbachia endosymbiont of Dirofilaria immitis, 16S rRNA gene. The trees were constructed by the neighbor-joining method and bootstrap values calculated from 1000 trees. The scale bar indicates the estimated number of substitutions per 100 and 500 nucleotides as indicated. All names and accession numbers are given as cited in the GenBank database. 


Ehrlichia canis
Ehrlichia muris
Ehrlichia ruminantium
Ehrlichia ovina
Ehrlichia chaffeensis
Ehrlichia ewingii
Wolbachia endosymbiont of Dirofilaria immitis

Ehrlichia canis

Ehrlichia muris

Ehrlichia ruminantium

Ehrlichia ovina

Ehrlichia chaffeensis

Ehrlichia ewingii

Wolbachia endosymbiont of Dirofilaria immitis

Ehrlichia canis

Ehrlichia muris

Ehrlichia ruminantium

Ehrlichia ovina

Ehrlichia chaffeensis

Ehrlichia ewingii

Wolbachia endosymbiont of Dirofilaria immitis
Forward 5 ' GTTAGTGGCAGACGGGTGA

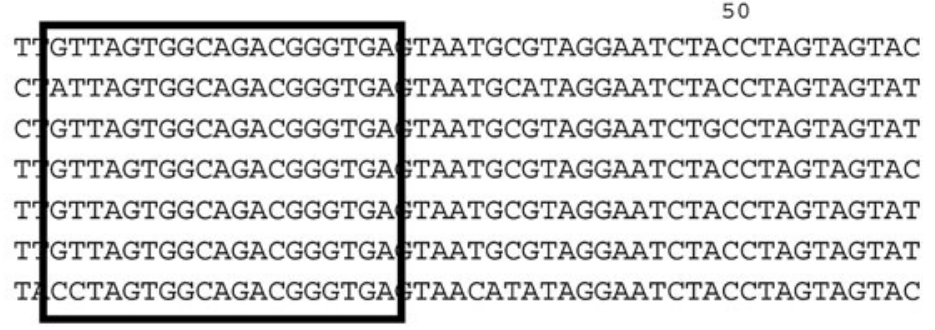

100

GGAATAGCCATTAGAAATGGTGGGTAATACTGTATAATCCCCGAGGGGGA GGAATAGCCATTAGAAATGATGGGTAATACTGTATAATCCCTGCGGGGGA GGAATAGCTATTAGAAATGATAGGTAATACTGTATAATCCCTGCGGGGGA GGAATAGCCATTAGAAATGGTGGGTAATACTGTATAATCCCCGAGGGGGA GGAATAGCCATTAGAAATGATGGGTAATACTGTATAATCCCTGCGGGGGA GGAATAGCCATTAGAAATGATGGGTAATACTGTATAATCCCTGCGGGGGA GGAATAATTGCTGGAAACGGCAGCTAATACCGTATACGCCCTATGGGGGA

FIG. 2. Nucleotide sequence alignment of $16 \mathrm{~S}$ rRNA gene of Ehrlichia spp. and Wolbachia endosymbiont of D. immitis, showing regions containing the $5^{\prime}$ and $3^{\prime}$ primers used for Ehrlichia polymerase chain reaction.

of the study, we did not perform blood film examination for microfilaremia and, hence, could not correlate the presence of Wolbachia DNAemia with microfilaremia. Although the use of antigen detection kits provides rapid results for immediate management decisions and most of the antigen detection tests are highly sensitive and specific (Nelson et al. 2005), PCR for D. immitis DNA is a potentially useful adjunct in cases with low levels of microfilaremia, as the sensitivity of antigen detection tests may be lowered in such cases (Vezzani et al. 2008). However, the added benefits of PCR over serology need to be demonstrated by further studies. On the other hand, in certain parts of the world where other filarial parasites are endemic, these point-of-care tests (primarily targeted against $D$. immitis) may not be clinically useful. With careful selection of primers and/or the use of sequencing, molecular testing could be a better diagnostic test in these areas where non-D. immitis filariases are common. Wolbachia PCR may provide additional information, because the sensitivity of D. immitis antigen detection tests could be limited in dogs with only male or young female worms, as the antigens are derived from the genital organs of adult female worms.

We found no evidence of active canine infection due to Rickettisa, O. tsutsugamushi, and B. burgdorferi in our cohorts. Although the role of dogs as a reservoir host for these bacteria in Hong Kong is probably minor, we cannot completely exclude their existence, because past infections may not be detectable by PCR and serologic tests are required for confirmation. Rickettsia felis is an emerging zoonotic pathogen in many parts of the world, with reservoirs in both the cats and dogs. B. burgdorferi sensu sticto is primarily found in North America and Europe, and the main vertebrate reservoir hosts are small mammals (especially rodents). However, both $B$. burgdorferi sensu sticto and sensu lato have been isolated from animals in mainland China and Taiwan (Chao et al. 2002, Zhang et al. 1997, Shih et al. 1998a, 1998b). Dogs and humans are accidentally infected by hard tick bites, though neither are important reservoir hosts.

In previous studies from Spain, France, Italy, Czech, the United Kingdom, and the United States, coinfection of vectorborne pathogens in dogs ranged from $0 \%$ to over $50 \%$, depending on the location, pathogens, and methods of detection (Shaw et al. 2005, Solano-Gallego et al. 2006, Amusategui et al. 2008, Beall et al. 2008, Kybicová et al. 2009, Pantchev et al. 2009, Couto et al. 2010, Otranto et al. 2010, Tzipory et al. 2010). Evidence of co-infection was found in 19\% of stray and 6\% pet dogs in our study $(p<0.01)$. The higher prevalence in stray dogs can be explained by the higher risk of exposure to arthropod vectors in the environment.

One of the most important limitations of the point-of-care test is the lack of testing for babesiosis, which is the commonest arthropod-borne infection in both pet and stray dogs in Hong Kong. Most of these are caused by B. gibsoni with only $7.3 \%$ due to B. canis. Although serologic diagnosis of babesiosis using immunofluorescent antibody testing is commercially available, it is rather cumbersome for most veterinarians and requires separate laboratory support. Canine babesiosis is 
a tick-borne infection with a global distribution caused by B. canis (subsp. canis, vogeli, and rossi), B. gibsoni, B. microti, B. equi, and B. conradae. B. gibsoni generally causes hemolytic anemia, fever, lethargy, hepatosplenomegaly, hemoglobinuria, and icterus. The other less important tick-borne infection is hepatozoonosis. As expected, the Old World species $H$. canis (transmitted by $R$. sanguineus) is the only species found in our study, though the pathogen is not common in our dog population. The absence of American canine hepatozoonosis (H. americanum) in Hong Kong is probably related to the absence of its tick vector Amblyomma maculatum. The American form of the disease is generally more severe, and infected animals are more debilitated and often fatal

Compared with conventional blood film examination, PCR offers a highly sensitive means for detecting blood-borne pathogens. A broad range of pathogens can be detected by PCR studies. Sequencing studies also allow differentiation of species or subspecies that may have similar morphological appearances. The accurate speciation of the pathogens carries epidemiologic or prognostic significance. Molecular studies allow the detection of newly described pathogens for which serologic tests are generally not available. However, at the moment, the turnaround time for molecular testing is still longer than blood film examination and point-of-care testing, and the availability of molecular diagnostics for veterinary service is still limited in many countries. A better organization and delivery of such techniques is highly desirable not just for better care of the sick animals but also to allow epidemiologic study of these pathogens and their zoonotic potentials.

\section{Acknowledgments}

This work is partly supported by the Consultancy Service for Enhancing Laboratory Surveillance of Emerging Infectious Disease for the Department of Health, Hong Kong; Tung Wah Group of Hospitals Fund for Research in Infectious Diseases; the Research Fund for the Control of Infectious Diseases of the Health, Welfare, and Food Bureau, Hong Kong; and the Providence Foundation Limited in memory of the late Dr. Lui Hac Minh. We are grateful for the generous support of Mrs. Carol Yu, Professor Richard Yu, The Hong Kong Sanatorium and Hospital, Mr. Hui Hoy, and Mr. Hui Ming in the genomic sequencing platform. The support of Mr. Alan C. K. Wong, Director of Agriculture, Fisheries, and Conservation, is indispensable to the project; and all the work from the staff of the Agriculture, Fisheries, and Conservation Department, Hong Kong, including Dr. Thomas Sit and Dr. Howard K. H. Wong, is gratefully acknowledged.

\section{Disclosure Statement}

No competing financial interests exist.

\section{References}

Amusategui, I, Tesouro, MA, Kakoma, I, Sainz, A. Serological reactivity to Ehrlichia canis, Anaplasma phagocytophilum, Neorickettsia risticii, Borrelia burgdorferi and Rickettsia conorii in dogs from northwestern Spain. Vector Borne Zoonot Dis 2008; 8:797-803.

Ayoob, AL, Hackner, SG, Prittie, J. Clinical management of canine babesiosis. J Vet Emerg Crit Care 2010; 20:77-89.
Bandi, C, Trees, AJ, Brattig, NW. Wolbachia in filarial nematodes: evolutionary aspects and implications for the pathogenesis and treatment of filarial diseases. Vet Parasitol 2001; 98:215238.

Bazzocchi, C, Genchi, C, Paltrinieri, S, Lecchi, C, et al. Immunological role of the endosymbionts of Dirofilaria immitis: the Wolbachia surface protein activates canine neutrophils with production of IL-8. Vet Parasitol 2003; 117:73-83.

Beall, MJ, Chandrashekar, R, Eberts, MD, Cyr, KE, et al. Serological and molecular prevalence of Borrelia burgdorferi, Anaplasma phagocytophilum, and Ehrlichia species in dogs from Minnesota. Vector Borne Zoonot Dis 2008; 8:455-464.

Beck, R, Vojta, L, Mrljak, V, Marinculic, A, et al. Diversity of Babesia and Theileria species in symptomatic and asymptomatic dogs in Croatia. Int J Parasitol 2009; 39:843-848.

Borgo, SN, Sattler, EC, Hogardt, M, Adler, K, et al. PCR analysis for Wolbachia in human and canine Demodex mites. Arch Dermatol Res 2009; 301:747-752.

Chao, LL, Shih, CM. Molecular characterization of Lyme disease spirochetes (Borrelia burgdorferi sensu lato) isolated in Taiwan by restriction fragment length polymorphism analysis of 5S(rrf)-23S(rrl) intergenic spacer amplicons. Am J Trop Med Hyg 2002; 67:504-510.

Couto, CG, Lorentzen, L, Beall, MJ, Shields, J, et al. Serological study of selected vector-borne diseases in shelter dogs in Central Spain using point-of-care assays. Vector Borne Zoonot Dis 2010; 10:885-888.

Demaerschalck, I, Ben Messaoud, A, De Kesel, M, Hoyois, B, et al. Simultaneous presence of different Borrelia burgdorferi genospecies in biological fluids of Lyme disease patients. J Clin Microbiol 1995; 33:602-608.

Dingman, P, Levy, JK, Kramer, LH, Johnson, CM, et al. Association of Wolbachia with heartworm disease in cats and dogs. Vet Parasitol 2010; 170:50-60.

Gioia, G, Lecová, L, Genchi, M, Ferri, E, et al. Highly sensitive multiplex PCR for simultaneous detection and discrimination of Dirofilaria immitis and Dirofilaria repens in canine peripheral blood. Vet Parasitol 2010; 172:160-163.

Inokuma, H, Yoshizaki, Y, Matsumoto, K, Okuda, M, et al. Molecular survey of Babesia infection in dogs in Okinawa, Japan. Vet Parasitol 2004; 121:341-346.

Irwin, PJ. Canine babesiosis. Vet Clin North Am Small Anim Pract 2010; 40:1141-1156.

Kramer, L, Grandi, G, Leoni, M, Passeri B, et al. Wolbachia and its influence on the pathology and immunology of Dirofilaria immitis infection. Vet Parasitol 2008; 158:191-195.

Kybicová, K, Schánilec, P, Hulínská, D, Uherková, L, et al. Detection of Anaplasma phagocytophilum and Borrelia burgdorferi sensu lato in dogs in the Czech Republic. Vector Borne Zoonot Dis 2009; 9:655-661.

Lau, SK, Chan, KH, Yip, CC, Ng, TK, et al. Confirmation of the first Hong Kong case of human infection by novel swine origin influenza A (H1N1) virus diagnosed using ultrarapid, realtime reverse transcriptase PCR. J Clin Microbiol 2009; 47:23442346.

Lau, SK, Woo, PC, Li, KS, Huang, Y, et al. Severe acute respiratory syndrome coronavirus-like virus in Chinese horseshoe bats. Proc Natl Acad Sci USA 2005; 102:14040-14045.

Lau, SK, Woo, PC, Tse, H, Fu, CT, et al. Identification of novel porcine and bovine parvoviruses closely related to human parvovirus 4. J Gen Virol 2008; 89:1840-1848.

Lau, SK, Woo, PC, Wong, BH, Wong, AY, et al. Identification and complete genome analysis of three novel para- 
myxoviruses, Tuhoko virus 1, 2 and 3, in fruit bats from China. Virology 2010; 404:106-116.

Lee, AC, Montgomery, SP, Theis, JH, Blagburn, BL, et al. Public health issues concerning the widespread distribution of canine heartworm disease. Trends Parasitol 2010; 26:168-173.

Lin, Q, Rikihisa, Y, Felek, S, Wang, X, et al. Anaplasma phagocytophilum has a functional $m s p 2$ gene that is distinct from $p 44$. Infect Immun 2004; 72:3883-3889.

Little, SE. Ehrlichiosis and anaplasmosis in dogs and cats. Vet Clin North Am Small Anim Pract 2010; 40:1121-1140.

Littman, MP. Canine borreliosis. Vet Clin North Am Small Anim Pract 2003; 33:827-862.

Massung, RF, Slater, KG. Comparison of PCR assays for detection of the agent of human granulocytic ehrlichiosis, Anaplasma phagocytophilum. J Clin Microbiol 2003; 41:717-722.

M'Ghirbi, Y, Ghorbel, A, Amouri, M, Nebaoui, A, et al. Clinical, serological, and molecular evidence of ehrlichiosis and anaplasmosis in dogs in Tunisia. Parasitol Res 2009; 104:767-774.

Murphy, GL, Ewing, SA, Whitworth, LC, Fox, JC, et al. A molecular and serologic survey of Ehrlichia canis, E. chaffeensis, and E. ewingii in dogs and ticks from Oklahoma. Vet Parasitol 1998; 79:325-339.

Nelson, CT, McCall, JW, Rubin, SB, Buzhardt, LF, et al. Executive Board of the American Heartworm Society. Guidelines for the diagnosis, prevention and management of heartworm (Dirofilaria immitis) infection in dogs. Vet Parasitol 2005; 133:255-266.

Otranto, D, Testini, G, Dantas-Torres, F, Latrofa, MS, et al. Diagnosis of canine vector-borne diseases in young dogs: a longitudinal study. J Clin Microbiol 2010; 48:3316-3324.

Pantchev, N, Schaper, R, Limousin, S, Norden, N, et al. Occurrence of Dirofilaria immitis and tick-borne infections caused by Anaplasma phagocytophilum, Borrelia burgdorferi sensu lato and Ehrlichia canis in domestic dogs in France: results of a countrywide serologic survey. Parasitol Res 2009; 105(Suppl 1): S101-S114.

Regnery, RL, Spruill, CL, Plikaytis, BD. Genotypic identification of rickettsiae and estimation of intraspecies sequence divergence for portions of two rickettsial genes. J Bacteriol 1991; 173:1576-1589.

Rossi, MI, Paiva, J, Bendas, A, Mendes-de-Almeida, F, et al. Effects of doxycycline on the endosymbiont Wolbachia in Dirofilaria immitis (Leidy, 1856)-naturally infected dogs. Vet Parasitol 2010; 174:119-123.

Satoh, H, Motoi, Y, Camer, GA, Inokuma, H, et al. Characterization of spotted fever group rickettsiae detected in dogs and ticks in Okinawa, Japan. Microbiol Immunol 2002; 46:257-263.

Shaw, SE, Binns, SH, Birtles, RJ, Day, MJ, et al. Molecular evidence of tick-transmitted infections in dogs and cats in the United Kingdom. Vet Rec 2005; 157:645-648.

Shih, CM, Chang, HM, Chen, SL, Chao, LL. Genospecies identification and characterization of Lyme disease spirochetes of genospecies Borrelia burgdorferi sensu lato isolated from rodents in Taiwan. J Clin Microbiol 1998a; 36:3127-3132.
Shih, CM, Chao, LL. Lyme disease in Taiwan: primary isolation of Borrelia burgdorferi-like spirochetes from rodents in the Taiwan area. Am J Trop Med Hyg 1998b; 59:687-692.

Solano-Gallego, L, Llull, J, Osso, M, Hegarty, B, et al. A serological study of exposure to arthropod-borne pathogens in dogs from northeastern Spain. Vet Res 2006; 37:231-244.

Spolidorio, MG, la Bruna, MB, Zago, AM, Donatele, DM, et al. Hepatozoon canis infecting dogs in the State of Espírito Santo, southeastern Brazil. Vet Parasitol 2009; 163:357-361.

Thanchomnang, T, Intapan, PM, Lulitanond, V, Sangmaneedet, $\mathrm{S}$, et al. Rapid detection of Dirofilaria immitis in mosquito vectors and dogs using a real-time fluorescence resonance energy transfer PCR and melting curve analysis. Vet Parasitol 2010; 168:255-260.

Tzipory, N, Crawford, PC, Levy, JK. Prevalence of Dirofilaria immitis, Ehrlichia canis, and Borrelia burgdorferi in pet dogs, racing greyhounds, and shelter dogs in Florida. Vet Parasitol 2010; 171:136-139.

Unver, A, Rikihisa, Y, Kawahara, M, Yamamoto, S. Analysis of 16S rRNA gene sequences of Ehrlichia canis, Anaplasma platys, and Wolbachia species from canine blood in Japan. Ann NY Acad Sci 2003; 990:692-698.

Veir, JK, Lappin, MR. Molecular diagnostic assays for infectious diseases in cats. Vet Clin North Am Small Anim Pract 2010; 40:1189-1200.

Vezzani, D, Fontanarrosa, MF, Eiras, DF. Are antigen test kits efficient for detecting heartworm-infected dogs at the southern distribution limit of the parasite in South America? Preliminary results. Res Vet Sci 2008; 85:113-115.

Woo, PC, Lau, SK, Lam, CS, Lai, KK, et al. Comparative analysis of complete genome sequences of three avian coronaviruses reveals a novel group 3c coronavirus. J Virol 2009; 83:908-917.

Yuen, KY, Woo, PC, Teng, JL, Leung, KW, et al. Laribacter hongkongensis gen. nov., sp. nov., a novel Gram-negative bacterium isolated from a cirrhotic patient with bacteremia and empyema. J Clin Microbiol 2001; 39:4227-4232.

Zhang, ZF, Wan, KL, Zhang, JS. Studies on epidemiology and etiology of Lyme disease in China. Chin J Epidemiol 1997; 18:8-11.

Address correspondence to: Kwok-Yung Yuen State Key Laboratory of Emerging Infectious Diseases Department of Microbiology The University of Hong Kong Carol Yu Centre for Infection University Pathology Building

Queen Mary Hospital 102 Pokfulam Road Hong Kong

E-mail: kyyuen@hku.hk 
